\title{
NUCLEAR MAGNETIC RESONANCE SHIFT REAGENTS IN ORGANIC CHEMISTRY
}

\author{
Dudley H. Williams \\ University Chemical Laboratory, Lensfield Road, \\ Cambridge, CB2 1EW, UK
}

\begin{abstract}
The paper deals with the implications of shift reagents in organic chemistry in several broad areas. First, the relative binding affinities of common functional groups to shift reagents are considered, and it is shown that such knowledge aids the analysis of the shifted spectra of polyfunctional molecules and (by extension of the principles involved) isotopically substituted molecules. Secondly, the quantitative application of the pseudo-contact shift equation is considered, and the importance of considering the population of two or more energy minima associated with conformational mobility in the shift reagent/ substrate complex is emphasized. In the most adverse cases, observed shifts must be separated into (i) complex formation shifts (ii) contact shifts and (iii) pseudo-contact shifts. Thirdly, the potential of shift reagents in biology and ${ }^{13} \mathrm{C}$ n.m.r. is briefly outlined. Finally, some miscellaneous applications are given.
\end{abstract}

\section{INTRODUCTION}

Although it has long been recognized that paramagnetic ions can cause shifts of resonance signals in n.m.r. spectra, prior to 1969 the most spectacular results had been obtained in cases where the substrate was covalently bound to the paramagnetic metal ${ }^{1}$. However, in 1969 a breakthrough occurred when Hinckley ${ }^{2}$ discovered that addition of the pyridine adduct of europium dipivaloylmethane $\left[\mathrm{Eu}(\mathrm{dpm})_{3}, 1\right]$ to a carbon tetrachloride solution of cholesterol caused relatively large selective downfield shifts of some of the steroid proton resonances without adverse line broadening. It was soon shown ${ }^{3}$ that $\mathrm{Eu}(\mathrm{dpm})_{3}(\mathbf{1})$ is a superior shift reagent to its pyridine adduct, since substrates associate with the shift reagent through electron donation, e.g. (2), and competition to this weak association through availability of the pyridine lone pair is detrimental.

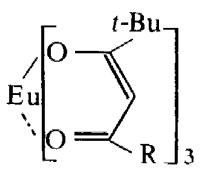

1. $\mathrm{R}=t-\mathrm{Bu}$

1a, $\mathrm{R}=\mathrm{CF}_{2} \mathrm{CF}_{2} \mathrm{CF}_{3}$

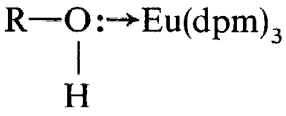

2

It was clear from many early experiments that the proton lanthanideinduced shifts are very largely pseudo-contacts in origin in the vast majority 
of cases. Thus, the proton shifts are normally due to a field effect of the paramagnetic ion, and not due to a direct nucleus-electron interaction (contact shift). Where shifts are solely pseudo-contact in origin, then equation I applies, provided that the metals have fast electronic relaxation times and that the substrate/shift reagent complex has effective axial symmetry ${ }^{4}$ : in equation (I), $r$ is the distance of the nucleus in question from the metal ion and $\theta$ the angle between the principal magnetic symmetry axis and the nucleus in question:

$$
\text { shift }=\text { constant }\left(\frac{3 \cos ^{2} \theta-1}{r^{3}}\right)
$$

Quantitative applications of equation (I) are considered later.

\section{RELATIVE BINDING STRENGTHS OF COMMON ORGANIC FUNCTIONALITIES}

If the induced shift for a given proton is plotted against molar ratio $M$ $\left(M=\left[\mathrm{Eu}(\mathrm{dpm})_{3}\right] /[\right.$ substrate $\left.]\right)$ in the range $0.1<M<0.5$, good straight lines are obtained. At low values of $M$ residual moisture can interfere ${ }^{5-7}$. The gradients $(G)$ of the straight line sections are roughly characteristic for any proton in a given relatively unhindered environment. Table 1 shows some typical values of $G$ (in p.p.m. per mole $\mathrm{Eu}(\mathrm{dpm})_{3}$ per mole substrate) for substrates dissolved in $\mathrm{CCl}_{4}$.

Table 1. Some typical $\mathrm{Eu}(\mathrm{dpm})_{3}$-induced $\mathrm{G}$ values for substrates in $\mathrm{CCl}_{4}$ solution

\begin{tabular}{|c|c|c|c|}
\hline Functionality & $G$ (p.p.m.) & Functionality & $G$ (p.p.m.) \\
\hline $\mathrm{RCH}_{2} \mathrm{NH}_{2}$ & 150 & $\mathrm{RCOOC}_{3}$ & 14 \\
\hline $\mathrm{RCH}, \mathrm{OH}$ & 100 & $\mathrm{RCH}, \mathrm{COOCH}_{3}$ & 13 \\
\hline $\mathrm{RCH}_{2} \mathrm{NH}_{2}$ & 35 & $\left(\mathrm{CH}_{3}\right)_{2} \mathrm{SO}$ & 8.9 \\
\hline $\mathrm{RCH}_{2} \mathrm{OH}$ & 25 & $\left(\mathrm{RCH}_{2} \mathrm{O}\right)_{3} \mathrm{PO}$ & 8.8 \\
\hline$\left(\mathrm{CH}_{3}\right)_{2} \mathrm{~N} \cdot \mathrm{CO} \cdot \underline{\mathrm{H}}$ & 34 & $(\mathrm{RO})_{2} \overline{\mathrm{PO}} \cdot \mathrm{CH}_{3}$ & 7 \\
\hline$\left(\mathrm{CH}_{3}\right)_{2} \mathrm{~N} \cdot \mathrm{CO} \cdot \overline{\mathrm{C}} \mathrm{H}_{3}$ & 12.5 & $\mathrm{RCH}_{2} \mathrm{CN}$ & 5 \\
\hline $\mathrm{RCO} \cdot \underline{\mathrm{H}}$ & 19 & $\left(\mathrm{RCH}_{2}\right)_{2} \mathrm{~S}$ & $<1$ \\
\hline$\left(\mathrm{RCH}_{2}\right)_{2} \mathrm{CO}$ & 11 & $\mathrm{RCH}_{2} \mathrm{OX} \dagger$ & $<1$ \\
\hline$\left(\mathrm{RC}_{2}\right)_{2} \mathrm{O}$ & 10 & & \\
\hline
\end{tabular}

$+\mathrm{X}=\mathrm{CPh}_{3}, \mathrm{COCF}_{3}$ or tosyl.

It is clear that there is at least a qualitative correlation between the values of $G$ and substrate basicity. It is noteworthy that $\mathrm{Eu}(\mathrm{dpm})_{3}$ is a 'hard' Lewis acid $^{8}$ and is virtually inert to 'soft' second-row bases such as S and P in sulphides and phosphines.

\section{EVALUATION OF OTHER LANTHANIDE COMPLEXES}

The dpm complexes of all the other lanthanides have also been evaluated as shift reagents ${ }^{9,10}$. Although some of the other lanthanides produce larger downfield shifts than $\mathrm{Eu}, \mathrm{Eu}(\mathrm{dpm})_{3}$ is the most commonly used 
reagent (among the dpm complexes) for downfield shifts, since it causes relatively little line broadening; $\operatorname{Pr}(\mathrm{dpm})_{3}$ finds favour for inducing upfield shifts. $\mathrm{Eu}(\mathrm{fod})_{3}\left(\mathbf{1 a}, \mathrm{R}=\mathrm{CF}_{2} \mathrm{CF}_{2} \mathrm{CF}_{3}\right)$ is a stronger Lewis acid than $\mathrm{Eu}(\mathrm{dpm})_{3}$ and more soluble than $\mathrm{Eu}(\mathrm{dpm})_{3}$ in common organic solvents, and is widely used as a shift reagent, especially when the substrate has a relatively low basicity.

\section{ANALYSIS OF THE SHIFTED SPECTRA OF POLYFUNCTIONAL MOLECULES}

Qualitative interpretation of the shifted spectra of substrates of known structure is normally a simple matter, but most n.m.r. problems deal with multifunctional molecules. To analyse the shifted spectra of such multifunctional molecules, two approaches may be employed. One is to 'turn off' one or more of the functionalities (i.e. make them inert to shift reagents) so that spectral interpretation is simplified. Alcohol functions can be inactivated by conversion to the corresponding trifluoracetate, trityl ether or tosylate (Table 1), while ketones or aldehydes may be inactivated by conversion to the corresponding ethylene thioketal ${ }^{11}$.

The second approach involves a consideration of the competition between various functionalities (in a given substrate) for the shift reagent. The spectra are clearly averages of the spectra in the free and bound states because of fast exchange, and in the case of monofunctional substrates we may consider the equilibrium process shown in equation (II):

$$
n(\text { substrate })+\mathrm{Eu}(\mathrm{dpm})_{3} \rightleftharpoons \text { adduct }
$$

In this case it has been shown for a number of substrates that $n=1^{7,12-15}$; this much (and relatively large values of the association equilibrium constant $K$ ) is evident from the well-documented sharp limit in shift at values of $M$ approaching unity. In the general case of a set $j$ of $x$ functional groups each with an independent equilibrium constant, $K_{j}$ and concentration, $S_{j}$, it may be shown ${ }^{7}$ that

$$
G\left(H_{k}\right)_{i}=\Delta_{\mathrm{lim}} \cdot\left(H_{k}\right)_{i} \cdot \frac{K_{i} S_{i}}{1+\sum_{j=1}^{x} K_{j} S_{j}}
$$

where $G\left(H_{k}\right)_{i}$ is the initial shift gradient of the $k$ th proton of the $i$ th substrate of the mixture, and $\Delta_{\text {lim }}\left(H_{k}\right)_{i}$ is the limiting shift of this proton. Applying this kind of analysis to a bifunctional compound such as methyl oleanate (3), one may predict that at low concentrations of the shift reagent, coordination will occur mainly at the $3 \beta$-hydroxyl group, but that as the $\mathrm{Eu}(\mathrm{dpm})_{3}$ concentration is increased, relatively more coordination should occur at the ester function (cf. relative $G$ values observed for alcohol and ester functions in Table 1). These predictions are strikingly confirmed by the data given in Figure $1^{7}$. Hence, relative $K$ values or qualitative guides to relative $K$ values (Table 1 ) may be used to predict which protons will be most affected at any given stage of a shift reagent experiment. 


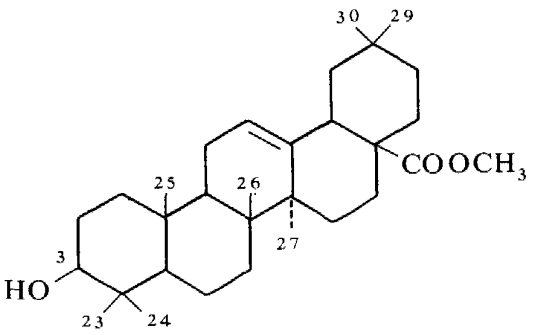<smiles>CC(C)C(C)(C)O</smiles>

3

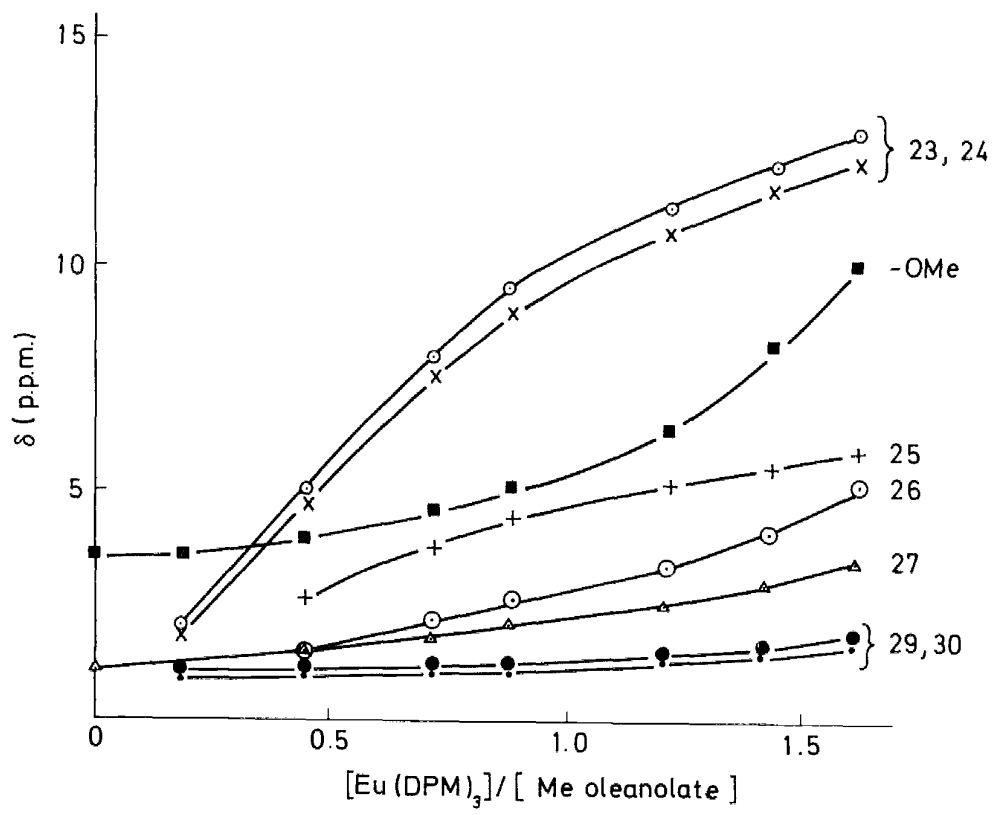

Figure I. The effect of added $\mathrm{Eu}(\mathrm{dpm})_{3}$ on the methyl resonances of methyl oleanate (3) (approximately $0.09 \mathrm{M}$ in $\mathrm{CCl}_{4}$ solution).

\section{DEUTERIUM ISOTOPE EFFECTS}

Through application of equation (III), relative equilibrium constants in a mixture can be determined with a precision of about $0.1 \%$ in $K_{\mathrm{A}} / K_{\mathrm{B}}$. For example, it can be shown ${ }^{16}$ by the use of $\mathrm{Eu}(\mathrm{dpm})_{3}$ in n.m.r. competition experiments that replacement of protium by deuterium in methyl A of (4) increases the stability of the Eu(dpm $)_{3}$ adduct by $3.45( \pm 0.21) \mathrm{cal} \mathrm{mol}^{-1}$ deuterium, whereas substitution in methyl B gives only a stabilization of $0.75( \pm 0.08) \mathrm{cal} \mathrm{mol}^{-1}$ deuterium. Other studies of isotope effects have been reported by de Boer et al. ${ }^{17}$ and Hinckley et al. ${ }^{18}$. 


\section{QUANTITATIVE APPLICATION OF THE PSEUDO-CONTACT SHIFT EQUATION (EQUATION I)}

Before equation (I) can be applied to experimental shifts, it is necessary to establish that:

(i) 'complex formation shifts' do not occur with the diamagnetic reagent $\mathrm{La}(\mathrm{dpm})_{3}$;

(ii) the shifts, after correction for any 'complex formation shifts', are pseudo-contact in origin, and the complex has effective axial symmetry; and

(iii) the shifts do not arise from an averaging over many different structures.

These checks are now considered in turn.

(i) Although it has been reported ${ }^{19}$ that cholesterol gives no measurable shifts upon addition of $\mathrm{La}(\mathrm{dpm})_{3}$, significant shifts are observed for the ${ }^{13} \mathrm{C}$ nucleus directly bonded to oxygen in some alcohols (3-5 p.p.m. per mole $\mathrm{Ln}(\mathrm{dpm})_{3}$ per mole substrate), and large shifts are observed for the ${ }^{13} \mathrm{C}$ nucleus of the carbonyl carbon of some ketones (7-12 p.p.m. per mole $\operatorname{Ln}(\mathrm{dpm})_{3}$ per mole substrate) (all downfield shifts) ${ }^{20}$. Where such 'complex formation shifts' are observed, an appropriate correction must be made to the experimentally observed shifts, on the assumption that the "complex formation shift' will be the same for the paramagnetic ion.

(ii) If the reasonable assumption is made that, notwithstanding the lanthanide contraction, various $\operatorname{Ln}(\mathrm{dpm})_{3}$ reagents form complexes with closely similar Ln-heteroatom bond lengths (in the case of a given monofunctional substrate at least), then the shift ratio observed for any nucleus with two different $\mathrm{Ln}^{3+}$ ions will be constant in those cases where equation (I) applies. For example, the observation ${ }^{19}$ that the various protons and carbons of cholesterol give constant $\operatorname{Eu}(\mathrm{dpm})_{3} / \mathrm{Dy}(\mathrm{dpm})_{3}$ experimental shift ratios is consistent with the exclusive occurrence of pseudo-contact shifts in a complex which has effective axial symmetry. This experimental check is best carried out with reagents that cause shifts in opposite directions, e.g. $\mathrm{Eu}^{3+}$ or $\mathrm{Yb}^{3+}$ with $\mathrm{Pr}^{3+}$ or $\mathrm{Dy}^{3+}$. The above results on the direct experimental data for cholesterol imply that no shifts should be induced by $\mathrm{La}(\mathrm{dpm})_{3}$, as is indeed observed-see (i).

(iii) The problem of establishing that shifts do not arise from an averaging over many different structures is an extremely difficult one. Three situations may be considered. The first, and simplest, is that where the substrate is conformationally rigid. The problem can be exemplified by reference to 4-t-butylcyclohexanone (5) as substrate. If ${ }^{1} \mathrm{H}$ and ${ }^{13} \mathrm{C}$ shifts caused by $\mathrm{Yb}(\mathrm{dpm})_{3}$ are used to determine the metal position by means of a computer search (see below), simultaneously trying to satisfy the identical shifts of $\mathrm{C}-2$ and $\mathrm{C}-6, \mathrm{C}-3$ and $\mathrm{C}-5$, etc., then the metal position is determined as lying on the twofold axis (5).

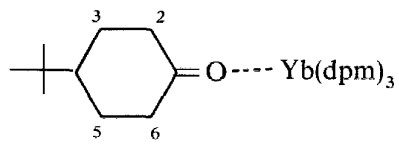

5

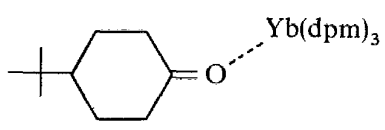

6 
However, the computer search should correctly be carried out in a way which reflects each $\mathrm{Yb}^{3+}$ position through the twofold axis and then weights these reflected solutions equally. When the search is carried out in this way, superior solutions are obtained where the $\mathrm{Yb}(\mathrm{dpm})_{3}$ appears to coordinate into the lone pair electrons of the carbonyl group. Thus, the observed shifts are due to an equal weighting of two structures (see 6).

The second situation is one where it may be considered that a single orientation of the metal-heteroatom bond can be defined, but that there is conformational mobility of the substrate. For example, the n.m.r. data resulting from lanthanide-induced pseudo-contact shifts have been used to determine the conformation of adenosine monophosphate (7) in solution ${ }^{21}$.

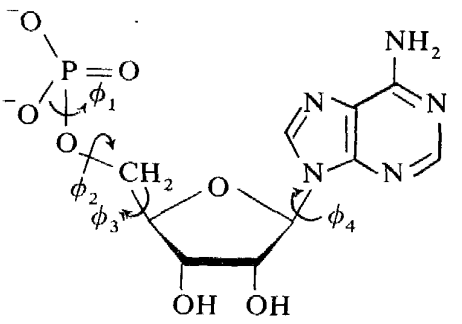

7

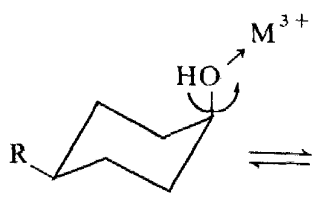

A

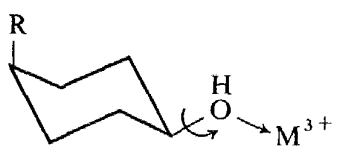

B

The molecule (7) has four torsion angles which must be determined, and the lanthanide-induced shifts were experimentally determined for five protons distributed throughout the structure. In a computer search to fit the data the total amount of computing time involved can be drastically reduced by considering the molecule to be built up of a series of rigid units connected by the bonds about which rotation is allowed (see $\phi_{1}, \phi_{2}, \phi_{3}$ and $\phi_{4}$ in 7); constraints such as those imposed by van der Waals interactions may then be applied before the generation of the whole molecule is complete.

The third situation is one where there may be two or more energy minima as the shift reagent is rotated about, say, the $\mathrm{C}-\mathrm{O}$ bond of a substrate (see 8) and simultaneously there is conformational mobility in the substrate, such as may occur in a cyclohexane ring system where both chair conformations may be populated. In these cases the correct fit of the data can only be obtained by appropriate relative weighting of the $8 \mathrm{~A}$ and $8 \mathrm{~B}$ chair conformations and appropriate weighting (including reflection about twofold axes) of energy minima corresponding to rotation about the $\mathrm{C}-\mathrm{O}$ bonds; these minima may be approximately determined by computer programs which calculate non-bonded interactions as a function of torsion angle.

It is possible to simplify the computational problem through use of the nitrile function ${ }^{22}$, and this case may serve to illustrate one method of fitting data via computational methods ${ }^{23}$ (an area initially explored by the Queen Mary College group ${ }^{24,25}$ ). The coordinating heteroatom may be taken as origin of a system of coordinates and the lanthanide metal $\mathbf{M}$ moved over a sphere of radius $r$ (the assumed $\mathrm{X}-\mathrm{M}$ distance) through variation of the angles $\phi$ and $\psi$. 


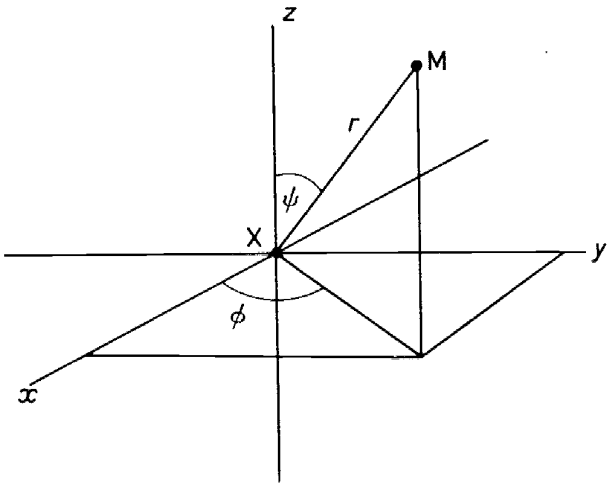

The function $\left(3 \cos ^{2} \theta_{i}-1\right) / r_{i}^{3}$ is evaluated for each proton (or other nucleus). In general, the magnetic axis of the complex may be assumed to be along the $\mathrm{X}-\mathrm{M}$ vector or allowed to vary during the search through the introduction of two additional angular variables ${ }^{19}$. In the program of Willcott et al. ${ }^{23}$ the set of numbers obtained by evaluating $\left(3 \cos ^{2} \theta_{i}-1\right) / r_{i}^{3}$ for each proton is then scaled by least squares against the relative observed shifts $(\Delta H / H)_{\mathrm{o} i}$ to yield a set of calculated shifts $(\Delta H / H)_{\mathrm{c} i}$. An agreement factor $R$ is then evaluated according to equation (IV):

$$
R=\left[\frac{\sum_{i}\left[(\Delta H / H)_{\mathrm{oi}}-(\Delta H / H)_{\mathrm{c} i}\right]^{2}}{\sum_{i}\left(\Delta H / H_{\mathrm{o} i}\right)^{2}}\right]^{\frac{1}{2}}
$$

$R$ is of course a measure of the 'goodness of the fit', and if one attempts to fit a set of data to two different structures, then the different agreement factors that will be obtained must be assessed in the light of the number of data points and the number of variables allowed in fixing the position of the metal. To illustrate this point, one may consider the $R$ values obtained by fitting the four sets of data from four nitriles (9-12) to the coordinates appropriate to each structure, i.e. taking all possible binary combinations (Table 2).
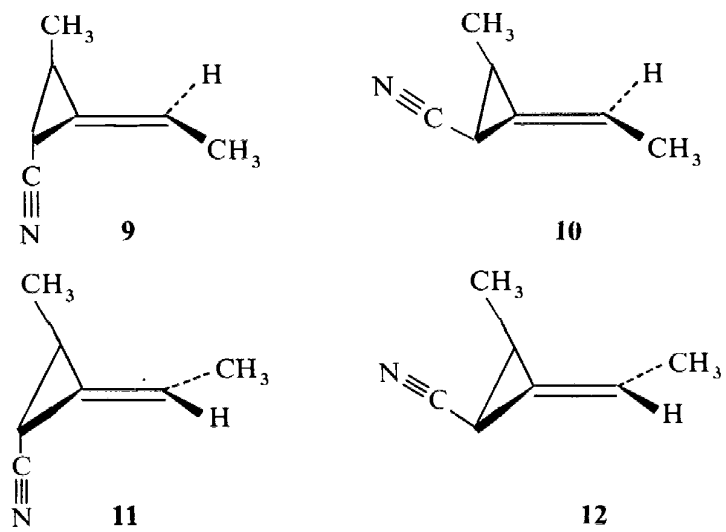
DUDLEY H. WILLIAMS

Table 2. Minimum $R$ values (\%) for binary combination of coordinates of 9-12 with data for 9-12[Eu(fod $)_{3}$ shifts]

\begin{tabular}{|c|c|c|c|c|}
\hline & & & & \\
\hline & 9 & 10 & 11 & 12 \\
\hline Model 9 & 4.2 & 22.0 & 12.6 & 31.0 \\
\hline Model 10 & 15.0 & 6.2 & 20.1 & 10.1 \\
\hline Model 11 & 13.2 & 25.7 & 4.7 & 20.1 \\
\hline Model 12 & 21.0 & 12.2 & 14.8 & 4.7 \\
\hline $\begin{array}{l}\text { Confidence level }(\%) \\
\text { for rejection of } \\
\text { second-best model }\end{array}$ & 20 & 34 & 24 & 31 \\
\hline
\end{tabular}

The question of course arises as to the confidence level at which, say, a second-best model may be rejected relative to the best model. In significance testing of the agreement factor $R$, Davis and Willcott ${ }^{26}$ use the following statistical criterion: rejection of a hypothesis at a given confidence level $\alpha \%$ means that we risk rejecting a true hypothesis $\alpha \%$ of the time (last row, Table 2). The $\mathrm{C}-\mathrm{N}-\mathrm{Eu}$ angles for minimum $R$ consistently reveal angles less than $10^{\circ}$ for each best model (i.e. for the correct solutions) and larger angles $\left(>30^{\circ}\right)$ at the 12 larger values of $R$. Thus, the physically real situations correspond to linear (or nearly linear) $\mathrm{Eu}-\mathrm{N}-\mathrm{C}$ bonds. It is profitable to use this conclusion in restraining of the metal to 'physically reasonable' position (supported by the above experimental data); reducing the number of parameters which can be varied in fixing the metal position increases the confidence level at which second-best solutions can be rejected (Table 3). This is despite the fact that $R$ is increased for the correct solution (Table 3) (since we now have fewer options for the metal position with the restraint of a linear $\mathrm{Eu}-\mathrm{N}-\mathrm{C}$ bond).

Table 3. Minimum $R$ values $(\%)$ for binary combinations as in Table 2, but with colinearity restraint

\begin{tabular}{|c|c|c|c|c|}
\hline \multirow[b]{3}{*}{ Model 9} & \multicolumn{4}{|c|}{ Data for } \\
\hline & 9 & 10 & 11 & 12 \\
\hline & 8.3 & 27.0 & 13.4 & 26.9 \\
\hline Model 10 & 22.3 & 6.5 & 26.0 & 12.0 \\
\hline Model 11 & 14.1 & 28.7 & 8.4 & 25.2 \\
\hline Model 12 & 25.8 & 12.6 & 22.7 & 6.7 \\
\hline $\left.\begin{array}{l}\text { Confidence level }(\%) \\
\text { for rejection of } \\
\text { second-best model }\end{array}\right\}$ & 10 & 7 & 11 & 8 \\
\hline
\end{tabular}

In summary, it will be evident from the foregoing discussion that the quantitative application of the McConnell-Robertson equation ${ }^{4}$ must be undertaken only with great care. Effective axial symmetry of the shift reagent-substrate complex results (and, hence, in the case of purely pseudocontact shifts, the equation is applicable) if the substrate ligand undergoes free rotation about an axis passing through the lanthanide ion or if it forms 
three (or more) interconverting rotamers which are equally populated ${ }^{27}$. In considering rotational motion about the bond connecting the coordinating heteroatom to the remainder of the substrate, the population of two or more energy minima may be important and the fits must consider appropriate averaging ${ }^{28,29}$. In these cases scans based on a unique metal position will give false solutions. The computational problem may be simplified by searching only those metal positions which correspond to reasonable $\mathrm{M}-\mathrm{X}$ bond lengths and $\mathrm{M}-\mathrm{X}-\mathrm{C}$ bond angles, e.g. consideration of association due to lone pair electrons. Conformational mobility in the substrate complicates the problem further.

In view of the above problems in the quantitative interpretation of shift data, it is generally desirable to check that any conclusions so derived are consistent with data available from experiments using 'relaxation reagents'. For example, $\mathrm{Gd}^{3+}$ has a relatively slow electron relaxation time and causes selective line broadening of resonances in the n.m.r. spectrum, since the broadening is $r^{-6}$-dependent, where $r$ is the distance from $\mathrm{Gd}^{3+}$ to the relevant nucleus. Thus, the use of $\mathrm{Gd}^{3+}$ allows a direct check on values of $r$ (derived from shift experiments) independent of $\theta$.

\section{THE STUDY OF SYSTEMS OF BIOLOGICAL INTEREST}

Studies of the solution conformation of AMP have been previously mentioned in this paper, but the general implications of shift reagents (and relaxation reagents) in biology are much wider. In polar solvents the free rare earth ions may be used, but unfortunately strong coordination only occurs at very basic functional groups such as phosphates, phosphonates $^{7,21,30,31}$, carboxylates ${ }^{32,33}$, and the oxides of amines, phosphines and arsines ${ }^{7}$. The potential for studying small molecules in polar media is therefore relatively limited, but fortunately lanthanide ions can frequently substitute for $\mathrm{Ca}^{2+}$ and $\mathrm{Mg}^{2+}$ in biological systems while retaining physiological activity ${ }^{34,35}$. Thus, the difference spectrum between free lysozyme and the $\mathrm{Gd}^{3+} /$ lysozyme complex consists of resonances of the protons nearest to the $\mathrm{Gd}^{3+}$ which is known to bind to the active site ${ }^{36}$. At low $\mathrm{Gd}^{3+}$ concentration very few protons are observed, and on addition of a shift probe, e.g. $\mathrm{Eu}^{3+}$, the movement of these resonances can be followed. The resulting relaxation and shift data permit a determination of the position in space of these protons relative to the metal. In the case where the use of probes bound to a single site does not define a unique structure, it may be necessary to bind probes to different sites. For example, in the case of hen egg white lysozyme the anion $\mathrm{Cr}(\mathrm{CN})_{6}^{3-}$ has been used.

The interaction of paramagnetic ions with lipid bilayer membranes gives particularly dramatic results ${ }^{37}$. The normal proton n.m.r. spectrum of lecithin in the form of a sonicated dispersion in $\mathrm{D}_{2} \mathrm{O}$ shows a sharp singlet at $\delta 3.6$ due to the choline $\stackrel{+}{\mathrm{N}} \mathrm{Me}_{3}$ group. Addition of $\mathrm{Eu}^{3+}$ causes this singlet to split into two peaks as shown in Figure 2(a). This is because the lecithin is in the form of bilayered micelles and the added ions are able to interact only with the external surface, presumably at the phosphate group. Addition of $\mathrm{Mn}^{2+}$ ions to this solution broadens only the resonance shifted by $\mathrm{Eu}^{3+}$ 
[Figure 2(b)], giving further proof that the inside and outside layers are not in rapid exchange with each other and that they are impermeable to these metal ions.

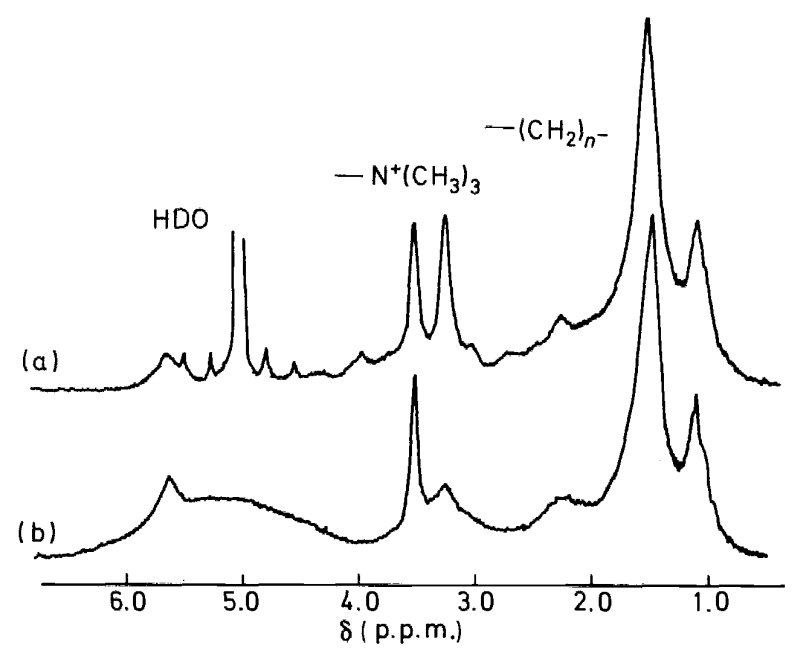

Figure 2. ${ }^{1} \mathrm{H}$ n.m.r. spectra of a $5 \% \mathrm{w} / \mathrm{v}$ dispersion of egg yolk lecithin in $\mathrm{D}, \mathrm{O}$ : (a) after addition of $2 \times 10^{-2} \mathrm{M} / 1 \mathrm{Eu}\left(\mathrm{NO}_{3}\right)_{3}$; (b) after addition to sample (a) of $3 \times 10^{-3} \mathrm{M} / 1 \mathrm{MnSO}_{4}$ (from ref. 37 ).

\section{SEPARATION OF CONTACT AND PSEUDO-CONTACT CONTRIBUTIONS, AND THE POTENTIAL OF SHIFT REAGENTS IN ${ }^{13} \mathrm{C}$ NMR SPECTROSCOPY}

As mentioned in the Introduction, a purely pseudo-contact mechanism normally satisfies the shifts observed in ${ }^{1} \mathrm{H}$ spectra. If, in the case of rigid substrates, these ${ }^{1} \mathrm{H}$ data are used to determine the metal position, then the pseudo-contact ${ }^{13} \mathrm{C}$ shifts can be calculated from the known metal position. If this procedure is followed for exo-norbornylamine (13) as substrate and $\mathrm{Eu}(\mathrm{dpm})_{3}$ as shift reagent, large deviations between observed and calculated (pseudo-contact) shifts are found only for C-1, C-2 and C-3; these differences (an upfield deviation being given a positive value) are, respectively, +41 , -39 and +11 p.p.m. Thus, at C-1 the anticipated pseudo-contact downfield shift is in fact observed as an upfield shift (i.e. a 'wrong way' shift) ${ }^{38}$. Roberts and co-workers have observed this 'wrong way' shift for $\beta$-carbon atoms with $\mathrm{Eu}(\mathrm{dpm})_{3}$ and $\mathrm{Eu}(\mathrm{fod})_{3}$ and several primary amine substrates; $\mathrm{Eu}^{3+}$

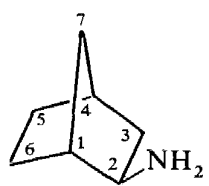

13<smiles>CCC(C)N</smiles> 
is much worse in causing these anomalies than $\operatorname{Pr}^{3+}$, and experience shows that more heavily substituted $\beta$-carbons are especially susceptible to abnormal shifts. For example, 2-butylamine (14) gives the lanthanide-induced ${ }^{13} \mathrm{C}$ shifts recorded in Table $4^{38}$.

Table 4. Lanthanide-induced ${ }^{13} \mathrm{C}$ shifts (in p.p.m.) for 2-butylamine (14)

\begin{tabular}{|c|c|c|c|c|}
\hline & $\mathrm{CH}_{3}-$ & $\left.\right|_{\mathrm{CH}} ^{\mathrm{NH}_{2}}$ & $-\mathrm{CH}_{2}-$ & $\mathrm{CH}_{3}$ \\
\hline $\begin{array}{l}\text { Eu(dpm })_{3} \\
\text { Eu(fod })_{3} \\
\operatorname{Pr}(d p m)_{3} \\
\operatorname{Pr}(\text { fod })_{3}\end{array}$ & $\begin{array}{l}-24.2 \\
-12.7 \\
+54.5 \\
+49.9\end{array}$ & $\begin{array}{r}-90.2 \\
-81.9 \\
+121.0 \\
+111.0\end{array}$ & $\begin{array}{l}+11.0 \\
+23.6 \\
+34.6 \\
+27.7\end{array}$ & $\begin{array}{r}-14.4 \\
-8.9 \\
+23.9 \\
+23.6\end{array}$ \\
\hline $\mathrm{La}(\mathrm{dpm})_{3}$ & +2.1 & $\sim 0$ & -0.6 & +0.2 \\
\hline
\end{tabular}

The anomalous ${ }^{13} \mathrm{C}$ shifts are due to contact contributions to the observed shifts, and these contact contributions at the $\alpha$ - and $\beta$-carbons and their alternating nature have been interpreted in terms of hyperconjugation ${ }^{38}$. Delocalization of a nitrogen electron to the metal as shown below would produce a radical electronically similar to the allyl radical, with positive spin density on the end carbons and negative spin density on the middle carbon. The contributing form (15) is believed to be unimportant, since contact shifts for ${ }^{1} \mathrm{H}$ are zero or negligible in these systems. The resonance form (16) should be a more important contributor the more heavily substituted the $\beta$-carbon, since increasing substitution renders the form energetically more favourable.

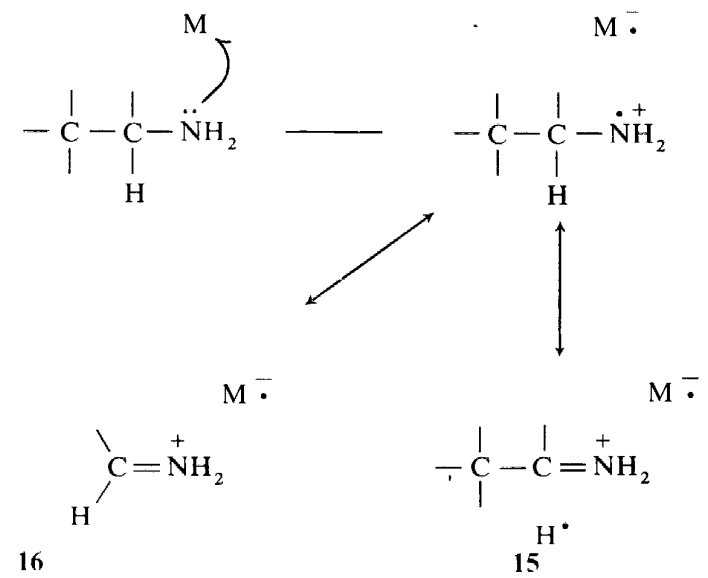

The contact shifts for ${ }^{13} \mathrm{C}$ nuclei of course complicate the use of shift reagents in structural and conformational problems. Fortunately, contact shifts are much smaller for the corresponding carbons of alcohols ${ }^{20 a}, 38$ and for ketones ${ }^{20 a}$. Contact contributions to observed shifts may be further 
reduced by using $\mathrm{Yb}(\mathrm{dpm})_{3}$ as shift reagents, since contact contributions lie in the order $\mathrm{Eu}(\mathrm{dpm})_{3}>\operatorname{Pr}(\mathrm{dpm})_{3}>\mathrm{Yb}(\mathrm{dpm})_{3}{ }_{3}^{20 \mathrm{a}, 20 \mathrm{~b}, 38}$.

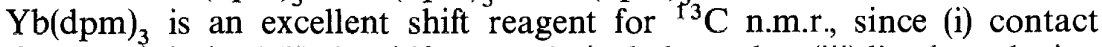
shifts are minimized (ii) the shifts are relatively large, but (iii) line broadening is not a serious problem. $\mathrm{Yb}(\mathrm{dpm})_{3}$ is extremely useful in assigning resonances in ${ }^{13} \mathrm{C}$ spectra, and its use in conjunction with $\mathrm{Gd}(\mathrm{dpm})_{3}$ permits calculation of relative distances and angles of ${ }^{13} \mathrm{C}$ atoms from a site of complexation, thus facilitating the determination of the carbon skeleton of an unknown ${ }^{20 \mathrm{a}}$. The principles of this approach may be illustrated by the hypothetical problem of partial determination of the structure of vitamin $\mathrm{D}_{3}(\mathbf{1 7})$ by reference to its ${ }^{13} \mathrm{C}$ n.m.r. spectrum (Figure 3), the corresponding offresonance spectrum (see, for example, the superimposed trace for the olefinic carbons in Figure 3), its ${ }^{1} \mathrm{H}$ spectrum, and the corresponding spectra obtained with $\mathrm{Gd}(\mathrm{dpm})_{3}$ as a relaxation reagent and $\mathrm{Yb}(\mathrm{dpm})_{3}$ as a shift reagent.

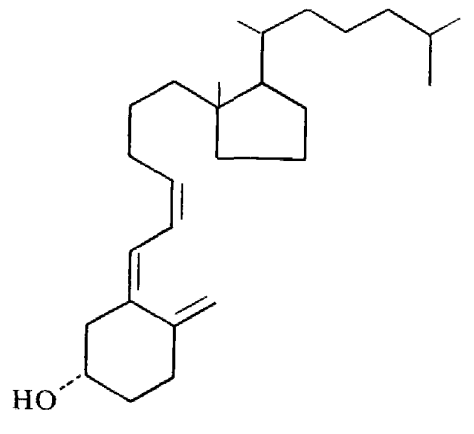

17

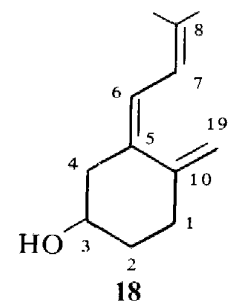

18

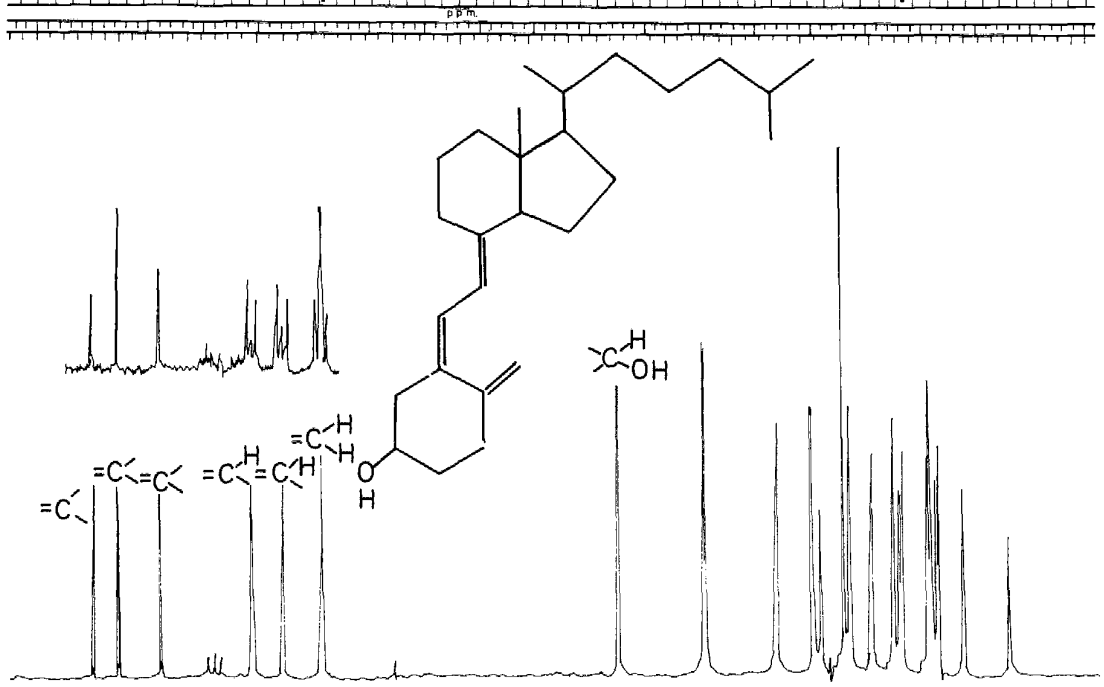

Figure $3 .{ }^{13} \mathrm{C}$ natural abundance Fourier transform n.m.r. spectrum of vitamin $\mathrm{D}_{3}$ (cholecaliferol) in $\mathrm{CDCl}_{3}$ solution ( $\sim 0.7$ molar); superimposed trace shows olefinic carbons off-resonance decoupled. 
The relative distances of the various carbons from the metal associated at the secondary alcohol group (e.g. $r(\mathrm{C}-5)<r(\mathrm{C}-6) \simeq r(\mathrm{C}-10)<r(\mathrm{C}-19) \simeq$ $r(\mathrm{C}-7)<r(\mathrm{C}-8))$ from the typical ${ }^{13} \mathrm{C}$ line broadening effects presented in Figure $4(\mathrm{a})$ are evident from the relaxation effects caused by $\mathrm{Gd}(\mathrm{dpm})_{3}$. The ${ }^{13} \mathrm{C}$ and ${ }^{1} \mathrm{H}$ shifts caused by $\mathrm{Yb}(\mathrm{dpm})_{3}$ can be used to approximately define three-dimensional surfaces upon which each nucleus must lie, as indicated schematically in Figure 4(b). The combined $\mathrm{Gd}^{3+}$ and $\mathrm{Yb}^{3+}$ data suggest that C-6 must be rotated further from the magnetic axis of the complex than $\mathrm{C}-10$, and likewise that $\mathrm{C}-7$ must be rotated further from the magnetic axis of the complex than C-19. Since C-6 and C-7 carbons both constitute $\mathrm{C}-\mathrm{H}$ units in which the two protons are mutually vicinally coupled $\left({ }^{1} \mathrm{H}\right.$ spectrum), then both $\mathrm{C}-6$ and $\mathrm{C}-7$ units must be rotated away from the magnetic axis of the complex so as to be separated by a $\mathrm{C}-\mathrm{C}$ bond length. With additional use of the restrictions of the limits of $\mathrm{C}-\mathrm{C}$ bond lengths and the off-resonance data, the partial structure (18) is readily defined.

(a)

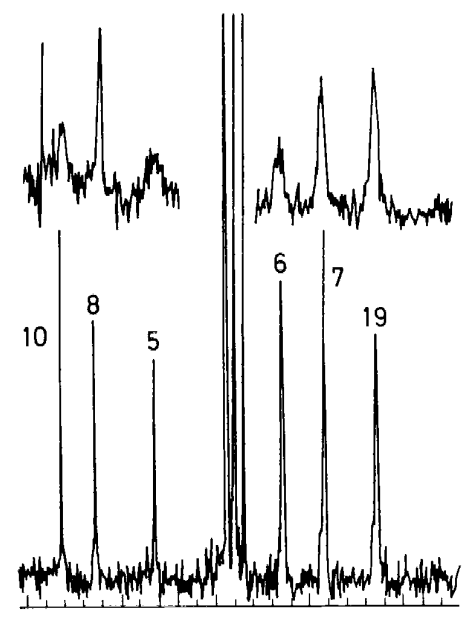

$\underline{\mathrm{Gd}^{3+} \text { results (distances) }}$

(b)

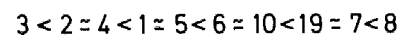

$$
\begin{aligned}
& \underline{Y b^{3+}} \text { results (shifts) } \\
& 3>2=4>1=5>10>\underset{\theta}{6}>19>7>8
\end{aligned}
$$

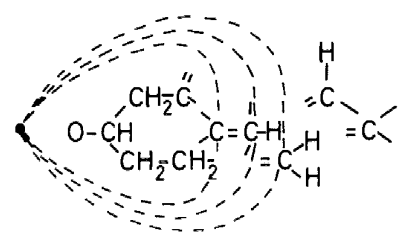

Figure 4. (a) Relative line broadening of the olefinic ${ }^{13} \mathrm{C}$ resonances of vitamin $\mathrm{D}_{3}$ upon addition of $\mathrm{Gd}(\mathrm{dpm})_{3}(\sim 0.01$ molar); (b) schematic illustration of surfaces upon which some $\mathrm{C}$ atoms of vitamin $\mathrm{D}_{3}$ must lie (from $\mathrm{Yb}(\mathrm{dpm})_{3}$-shifted spectra). 


\section{MISCELLANEOUS APPLICATIONS}

This paper has dealt largely with the principles of applying shift reagents in organic chemistry, rather than with the extremely large number of applications of the method to solving structural problems in small molecules. Many such applications are listed in excellent review articles ${ }^{39}$, and we will therefore refer only to a few selected examples.

Whitesides and Lewis ${ }^{40}$ prepared the chiral shift reagent tris-[3-( $t$-butylhydroxymethylene)- $\alpha$-camphorate] of europium $(\mathrm{Eu}(\mathrm{bhc}))(19 a)$ which with enantiomeric mixtures of amines gave shifted spectra in which all the protons of one isomer resonated at a lower field than those of the other. Shift reagents which are superior in resolving the n.m.r. spectra of many enantiomeric mixtures are 19b $\left(\mathrm{R}=\mathrm{CF}_{3}\right)^{41}$ and $19 \mathrm{c}\left(\mathrm{R}=\mathrm{CF}_{2} \mathrm{CF}_{2} \mathrm{CF}_{3}\right)^{41,42}$. Thus $19 \mathrm{~b}$ is useful in analysing the spectra of alcohols, ketones, esters, epoxides and amines.

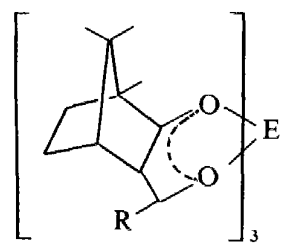

$19 \mathrm{a}, \mathrm{R}=t-\mathrm{Bu}$

$19 b, R=\mathrm{CF}_{3}$

$19 \mathrm{c}, \mathrm{R}=\mathrm{CF}_{2} \mathrm{CF}_{2} \mathrm{CF}_{3}$

Structural information is most commonly obtained via the use of shift reagents in two ways: (i) line overlap and chemical shift degeneracy may be removed to give additional information from line multiplicities, coupling constants and integrated areas or (ii) the pseudo contact shift equation (equation I) may be applied in a qualitative way. Examples of both methods are legion, but it is worth emphasizing that while results based on the first approach are normally secure, those based on the second may be unreliable because (a) angular variations are often ignored, and (b) even if angle variations are qualitatively considered, application of equation (I) in structural work requires care (see above). Reuben ${ }^{39}$ has rightly commented on the second approach that "conclusions reached in these studies should therefore be taken cum grano salis. A few of them may even be wrong'.

An example of the first approach is found in a study of the biosynthesis of squalene ${ }^{43}$. The cyclopropyl pyrophosphate (20a) was believed to be an intermediate in the biosynthesis of squalene, and an attempt to establish this intermediacy unambiguously was made through synthesis of the cyclopropyl alcohol (20b). The synthetic route led to a mixture of isomers: addition of $\mathrm{Eu}(\mathrm{dpm})_{3}$ to a $\mathrm{CDCl}_{3}$ solution of either isomer allowed the determination of the coupling constant between the two cyclopropyl protons $(J=5 \mathrm{~Hz}$ in one isomer and $J=9 \mathrm{~Hz}$ in the other), thus establishing the stereochemistry of the two products as depicted in $20 \mathbf{b}$ and 21 , respectively. The pyrophosphate (20a) was indeed biosynthetically incorporated into squalene.

Although applications of the type given above do not involve any new principles, it is such applications that have made shift reagents important to all organic chemists. A measure of the impact of shift reagents on the field 
<smiles>[R]C(C)=CC1C(C)C1([R])C</smiles>

20a, $X=O P P$
$20 b, X=O H$<smiles>[R]C(C)=CC1C(CO)C1([R])C</smiles>

21<smiles>[R]=C</smiles>

of organic chemistry is to be found in the fact that a list ${ }^{44}$ of the 30 papers, published in 1970, most frequently cited from 1970 to 1973 in the whole field of natural sciences contained three papers from the area of chemistry, and two of these ${ }^{3,6}$ were early announcements of the implications of shift reagents for organic chemistry. A similar list ${ }^{45}$ of the 251971 articles most cited in 1971 and 1972 contains three papers from the area of chemistry, and two of these $e^{5,46}$ again deal with shift reagents. These reagents certainly ensure that those researchers without superconducting magnets need no longer feel so underprivileged.

\section{ACKNOWLEDGEMENTS}

The author wishes to acknowledge the contributions, both conceptual and practical, of Dr J. K. M. Sanders and Dr D. J. Chadwick to the work carried out at the University Chemical Laboratory, Cambridge. He also thanks SRC and ICI for support of his co-workers.

\section{REFERENCES}

1 See, for example, E. De Boer and H. Van Willigen, Progress in N.M.R. Spectroscopy, 2, 111 (1967).

2 C. C. Hinckley, J. Amer. Chem. Soc. 91, 5160 (1969).

3 J. K. M. Sanders and D. H. Williams, Chem. Commun. 422 (1970).

4 H. M. McConnell and R. E. Robertson, J. Chem. Phys. 29, 1361 (1958).

5 J. K. M. Sanders and D. H. Williams, J. Amer. Chem. Soc. 93, 641 (1971).

6 P. V. DeMarco, T. K. Elzey, R. B. Lewis and E. Wenkert, J. Amer. Chem. Soc. 92, 5734 (1970).

7 J. K. M. Sanders, S. W. Hanson and D. H. Williams, J. Amer. Chem. Soc. 94, 5325 (1972).

8 R. G. Pearson, J. Amer. Chem. Soc. 85, 3533 (1963).

9 D. R. Crump, J. K. M. Sanders and D. H. Williams, Tetrahedron Letters, 4419 (1970).

${ }^{10}$ W. DeW. Horrocks and J. P. Sipe, J. Amer. Chem. Soc. 93, 6800 (1971).

11 D. R. Crump, J. K. M. Sanders and D. H. Williams, Tetrahedron Letters, 4949 (1970).

12 W. Wenkert, D. W. Cochran, E. W. Hagaman, R. B. Lewis and F. M. Schell, J. Amer. Chem. Soc. 93, 6271 (1971).

13 I. Armitage, G. Dunsmore, L. D. Hall and A. G. Marshall, Chem. Commun. 1281 (1971).

14 H. Huber and J. Seelig, Helv. Chim. Acta, 55, 135 (1972). 
15 D. G. Buckley, G. H. Green, E. Ritchie and W. C. Taylor, Chem. and Ind. (London), 298 (1971).

16 J. K. M. Sanders and D. H. Williams, Chem. Commun. 436 (1972).

17 A. M. Grotens, J. Smid and E. de Boer, Tetrahedron Letters, 4863 (1971).

18 G. V. Smith, W. A. Boyd and C. C. Hinckley, J. Amer. Chem. Soc. 93, 6319 (1971).

19 C. D. Barry, C. M. Dobson, D. A. Sweigart, L. E. Ford and R. J. P. Williams, in (R. E. Sievers ed.), Nuclear Magnetic Resonance Shift Reagents, p 173. Academic Press: New York (1973).

${ }^{20 a}$ D. J. Chadwick and D. H. Williams, unpublished work.

${ }^{20 b}$ For further studies of complex formation shifts, see K. Tori and Y. Yushimura, Tetrahedron Letters, 3127 (1973).

21 C. D. Barry, A. C. T. North, J. A. Glasel, R. J. P. Williams and A. V. Xavier, Nature (London), 232, 236(1971).

22 R. E. Davies, M. R. Willcott III, R. E. Lenkinski, W. von E. Doering and L. Bireadeanu, J. Amer. Chem. Soc. 95, 6846 (1973).

23 M. R. Willcott III, R. E. Lenkinski and R. E. Davis, J. Amer. Chem. Soc. 94, 1742 (1972).

24 J. Briggs, F. A. Hart and G. P. Moss, Chem. Commun. 1506 (1970).

25 J. Briggs, F. A. Hart, G. P. Moss and E. W. Randall, Chem. Commun. 364 (1971).

26 R. E. Davis and M. R. Willcott III, J. Amer. Chem. Soc. 95, 1744 (1973).

27 J. M. Briggs, G. P. Moss, E. W. Randall and K. D. Sales, Chem. Commun. 1180 (1972).

${ }^{28}$ I. M. Armitage, L. D. Hall, A. G. Marshall and L. G. Werbelow, J. Amer. Chem. Soc. 95, 1437 (1973).

29 R. M. Wing, J. J. Uebel and K. K. Andersen, J. Amer. Chem. Soc. 95, 6046 (1973).

30 J. K. M. Sanders and D. H. Williams, Tetrahedron Letters, 2813 (1971).

31 B. Birdsall, J. Feeney, J. A. Glasel, R. J. P. Williams and A. V. Xavier, Chem. Commun. $1473(1971)$.

${ }^{32}$ K. G. Morallee, E. Nieboer, F. J. C. Rossetti, R. J. P. Williams, A. V. Xavier and R. A. Dwek, Chem. Commun. 1132 (1970).

33 F. A. Hart, G. P. Moss and M. L. Staniforth, Tetrahedron Letters, 3389 (1971).

34 R. J. P. Williams, Quart. Rev. 24, 33 (1970).

35 G. E. Smolka, E. R. Birnbaum and D. W. Darnell, Biochemistry, 10, 4556 (1971).

36 I. D. Campbell, C. M. Dobson, R. J. P. Williams and A. V. Xavier, Proceedings of the Tenth Rare Earth Research Conference, 1972, p 791.

37 V. F. Bystrov, N. I. Dubovina, L. I. Barsukov and L. D. Bergelsor, Chem. Phys. Lipids, 6, $343(1971)$.

${ }^{38}$ G. E. Hawkes, C. Marzin, D. Leibfritz, S. R. Johns, K. Herwig, R. A. Cooper, D. W. Roberts and J. D. Roberts, in (R. E. Sievers ed.), Nuclear Magnetic Resonance Shift Reagents, p 129. Academic Press: New York (1973).

39 See, for example, J. Reuben in (J. W. Emsley, J. Feeney and L. H. Sutcliffe eds.) Progress in Nuclear Magnetic Resonance Spectroscopy, 9, 1 (1973).

40 G. M. Whitesides and D. W. Lewis, J. Amer. Chem. Soc. 92, 6979 (1970).

41 H. L. Goering, J. N. Eikenberry and G. S. Koermer, J. Amer. Chem. Soc. 93, 5913 (1971).

41 R. R. Fraser, M. A. Petit and J. K. Saunders, Chem. Commun. 1450 (1971).

43 L. J. Altman, R. C. Kowerski and H. C. Rilling, J. Amer. Chem. Soc. 93, 1782 (1971).

44 E. Garfield, Current Contents, No.51,5(1973).

45 E. Garfield, Current Contents, No. 44, 5 (1973).

46 R. E. Rondeau and R. E. Sievers, J. Amer. Chem. Soc. 93, 1522 (1971). 